\title{
Reaction of Lithium Cyanoaluminum Hydride with Selected Organic Compounds Containing Representative Functional Groups. Comparison of Reducing Characteristics between Lithium and Sodium Cyanoaluminum Hydrides
}

\author{
Jin Soon Cha and Se Jin Yu
}

\author{
Department of Chemistry, leungnam Lnversity, Gyoungsan 712-749, Korea. 'E-mail: ischatum.ac.kr \\ Received April 9. 2009. Accepted Mav 28. 2009
}

\begin{abstract}
Lithim cyanoaluninum hydride (LCAH) was prepared by the metal cation exchange reaction of sodium cyanoaluminum hydride with lithium chloride in tetrahydrofuran. The reducing characteristics of LCAH were explored systematically by the reaction with selected organic compounds containing representative functional groups under the standardized conditions (tetrahydrofuran, $0^{\circ} \mathrm{C}$ ). The reducing ability of $\mathbf{L C A H}$ was also compared with of the sodium derivative, sodium cyanoaluninum hydride (SCAH). Generally, the reducing behavior of LCAH resenbles that of SCAH closely, but the reactivity of LCAH toward representative organic functional groups appeared to be stronger than that of SCAH Thus, the regent reduces carbonyl compounds, epoxides, amides, nitriles, disulfides, carboxylic acids and their acyl derivatives to the corresponding alcohols or amines, at a relatively faster rate than that of SCAH The cyano substitution, a strong election-withdrawing group, diminishes the reducing power of the parent metal aluminum hydrides and hence effects the alteration of their reducing characteristics.
\end{abstract}

Key Words: Lithium cyanoaluminum hỵdride, Sodium aluninum hydride, Selective reduction organic functional groups. Systematic reduction study. Comparison of reducing characteristics

\section{Introduction}

Very recently; we reponted the systematic stidy on the approximate rates of reaction of sodium cyanoaluminum hydride (SCAH) ${ }^{1}$ with selected organic compounds and the comparison of it reducing characteristics with those of the parent sodium alumimum hydride (SAH). ${ }^{2}$ The reagent possesses a unique reducing characteristics. show ing a milder reactivity toward organic functional groups than that of SAH apparently due to the electron-withdrawing cyano group. This intrigued us. It seems desirable to explore the reducing characteristics of lithium cyanoalumimum hỵdride (LCAH) and compare its reduction pattern with that of sodium derivative (SCAH) and others. ${ }^{3}$ In this article. we wish to report the preparation and general reducing characteristics of $\mathbf{L C A H}$.

\section{Results and Discussion}

Prepanation of a Solution of Lithium Cyanoaluminum Hydride (LCAH) in THF. Lithium cyanoalumimum hydride (LCAH) was prepared by reacting sodium cyanoaluminum hydride (SCAH) in THF with LiCl wia metal cation exchange reaction. As $\mathrm{NaCl}$ precipitates out from the reaction mixture. a solution of $\mathrm{LCAH}$ in THF forms. The formation of $\mathrm{LiAlH}_{3} \mathrm{CN}$ was completed in $3 \mathrm{~h}$ at room temperature (Eq. 1). The $\mathrm{Al}$ NMR spectrum of LCAH in THF showed a broad singlet at ô 103 ppm relative to $\mathrm{Al}\left(\mathrm{H}_{2} \mathrm{O}\right)_{6}{ }^{39}$

$$
\begin{aligned}
& \mathrm{AlH}_{3}-\mathrm{NaCN} \stackrel{\mathrm{THF}}{\longrightarrow} \underset{\mathrm{SCAH}}{\mathrm{NaAlH}_{3} \mathrm{CN}}
\end{aligned}
$$

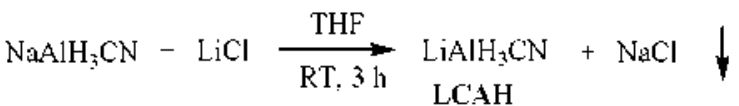

Aldehydes and Ketones (Table 1). All of the aldehydes and ketones exanined were reduced clearly to the alcohol stage within $0.5 \mathrm{~h}$ at $0^{\circ} \mathrm{C}$. There was no reactivity difference in the structure of carbonyls under the experimental conditions. As SCAH also readily reduces such simple carbonyl compounds to the corresponding alcohols. no significant difference in the reactivity owing to the metal cation exchange can be recognizable in these reactions.

$\alpha \beta$-Unsaturated Aldehydes and Ketones (Table 2). $\alpha . \beta$ Unsaturated aldehỳdes examined, such as crotonaldehỳde and cinnamaldehyde, were readily reduced by a limited amount of the reagent ( 0.34 equiv of $\mathbf{L C A H}$ : i.e. 1.0 equiv of hydride) to the corresponding allylic alcohols in an essentially $100 \%$ yield. However. excess hydride of the reagent (i.e. 1 equiv of LCAH : 3 equiv of hydride) attacked the carbon-carbon double bond. For instance. the reaction of cimmamaldehyde with 1 equiv of LCAH produced a mixture of cinnamyl alcohol (54\%) and hydrocinnantyl alcohol $(+6 \%)$. Further, the reaction of isophorone,

Table 1. Reaction of Representative Aldehydes and Ketones with Lithium and Sodium Cyanoaluminum Hydrides in Tetrahydrofuran at $0{ }^{\circ} \mathrm{C}^{a}$

\begin{tabular}{lccc}
\hline \multirow{2}{*}{ Compound } & Time (h) & \multicolumn{2}{c}{ Yields of alcohol $(\%)^{\mathrm{h}}$} \\
\cline { 3 - 4 } & & $\mathrm{LiAlH}_{3} \mathrm{CN}$ & $\mathrm{NaAlH}_{3} \mathrm{CN}^{c}$ \\
\hline caproaldehyde & 0.5 & 100 & 100 \\
benzaldehyde & 0.5 & 100 & 100 \\
2-heptanone & 0.5 & 100 & 100 \\
acetophenonle & 0.5 & 100 & 100 \\
benzophenone & 0.5 & 100 & 100 \\
norcamphor & 0.5 & $100^{\circ}$ & $100^{\alpha 2}$
\end{tabular}

"An equivalent of reagent utilized: $0.5 \mathrm{M}$ concentration. "Analyzed by GC with a suitable internal standard. 'Data takrn from ref. $1 .{ }^{d} \mathrm{~A} 0.34$ equivalent of reagent utilized. 
Table 2. Reaction of Representative $\alpha, \beta$-Unsaturated Aldehydes and Ketones with Lithium and Sodium Cyanoaluminum Hydrides in Tetrahydrofuranc ${ }^{a}$

\begin{tabular}{|c|c|c|c|c|c|c|c|}
\hline \multirow{3}{*}{ Compound } & \multirow{3}{*}{$\begin{array}{l}\text { Reagent/ } \\
\text { Compd }\end{array}$} & \multirow{3}{*}{$\begin{array}{c}\text { Temp. } \\
\left({ }^{\circ} \mathrm{C}\right)\end{array}$} & \multirow{3}{*}{$\begin{array}{l}\text { Time } \\
\text { (h) }\end{array}$} & \multicolumn{2}{|c|}{$\mathrm{LiAlH}_{3} \mathrm{CN}$} & \multicolumn{2}{|c|}{$\mathrm{NaAlH}_{3} \mathrm{CN}^{b}$} \\
\hline & & & & \multirow{2}{*}{$\begin{array}{c}\text { Total yield } \\
(\%)^{6}\end{array}$} & Product ${ }^{d}$ & \multirow{2}{*}{$\begin{array}{c}\text { Total yield } \\
(\%)^{c}\end{array}$} & Product ${ }^{2 t}$ \\
\hline & & & & & $1,2-: 1,4-$ & & $1,2-: 1,4-$ \\
\hline \multirow{2}{*}{ crotonaldehyde } & \multirow[t]{2}{*}{0.34} & \multirow[t]{2}{*}{0} & 0.5 & 100 & $100: 0$ & 98 & $100: 0$ \\
\hline & & & 6 & 100 & $100: 0$ & 98 & 1000 \\
\hline \multirow{2}{*}{ cinnamaldehyde } & 0.34 & 0 & 0.5 & 100 & $100: 0$ & 100 & 1000 \\
\hline & 1 & 0 & 24 & 100 & $54: 46$ & 100 & $20: 80$ \\
\hline \multirow{6}{*}{ isophorone } & \multirow[t]{4}{*}{0.34} & \multirow[t]{4}{*}{25} & 1 & & & 38 & \\
\hline & & & 6 & 78 & $14: 86$ & 41 & $25: 75$ \\
\hline & & & 12 & 89 & $15: 85$ & & \\
\hline & & & 24 & 99.6 & $15: 85$ & 52 & $48: 62$ \\
\hline & \multirow[t]{2}{*}{1} & \multirow[t]{2}{*}{0} & 12 & 99.9 & $2: 98$ & & \\
\hline & & & 24 & 99.8 & $2: 98$ & & \\
\hline
\end{tabular}

"A $0.5 \mathrm{M}$ concentration. "Data taken from ref. 1. "Analyzed by GC with a suitable intenal standard. "1.2-Product corresponds to allylic alcohol: 1.4-product corresponds to saturated alcohol. Normalized ratio.

a $\alpha \beta$-unsaturated ketone. even with a limited amount of the reagent produced a mixture of both 1,2- and 1.4-reduction products. Finally the reaction with excess hydride of LCAH afforded the 1,4-reduction product (the saturated alcohol). 3.3.5-trimethy lcy clohexanol. exclusively. The sodium derivative. SCAH also shows a similar trend. ${ }^{1}$ Thus, the reaction of cinnamaldehyde with a limited amount of SCAH afforded cinnamyl alcohol exclusively. however excess amount of the reagent produced both products. Similarly. the reaction of isophorone even with a limited amount of SCAH afforded a

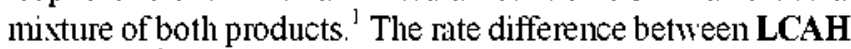
and $\mathrm{SCAH}^{\mathrm{l}}$ was first observed in the reduction of isophorone. Thus. LCAH reduced isophorone in $24 \mathrm{~h}$ at room temperature. but SCAH reduced only ca. $50 \%$ in that reaction period. ${ }^{1}$ Further. excess LCAH can reduce isophorone within $12 \mathrm{~h}$ even at $0^{\circ} \mathrm{C}$.

Stereochemistry in the Reduction of Cyclic Ketones (Table 3). The stereoselectivity of the reagent toward representative mono- and bicyclic ketones were also examined. The stereochemistry of LCAH showed a quite similar trend to that of SCAH ${ }^{l}$ which is usually obtained in the reaction with other

Table 3. Stereochemistry in the Reduction of Representative Cyclic Ketones with Lithimn and Sodium Cyanoalmminum Hydrides in Tetrahydrofuran at $0^{\circ} \mathrm{C}^{4}$

\begin{tabular}{|c|c|c|c|}
\hline \multirow{2}{*}{ Compound } & \multirow{2}{*}{$\begin{array}{l}\text { Time } \\
\text { (h) }\end{array}$} & \multicolumn{2}{|c|}{$\begin{array}{l}\text { Ratio of less stable } \\
\text { isomer }(\%)^{b}\end{array}$} \\
\hline & & $\mathrm{LiAlH}_{3} \mathrm{CN}$ & $\mathrm{NaAlH}_{3} \mathrm{CN}^{\mathrm{z}}$ \\
\hline 2-methylcyclohexanone & & $39^{c}$ & $43^{\circ}$ \\
\hline 3-methylcyclohexanone & & $20^{d}$ & $23^{d t}$ \\
\hline 4-methylcyclohexanone & & $16^{\circ}$ & $22^{c}$ \\
\hline 2-t-buthyloyclohexanone & & $61^{\circ}$ & $53^{\circ}$ \\
\hline 4-t-buthylcyclohexanone & & $9^{c}$ & $20^{c}$ \\
\hline 3,3,5-trimethyllcyclohexanone & & $79^{c}$ & $79^{r}$ \\
\hline norcanphor & & $91^{*}$ & $99.9^{\circ}$ \\
\hline camphor & & $92^{f}$ & $9 \mathrm{l}^{f}$ \\
\hline
\end{tabular}

"Total yields of alcohols are higher than $95^{\circ} \circ$, analyzed by GC. ${ }^{t}$ Normalized. 'Cis isomer. ${ }^{d}$ Trons isomer. "Ento isomer. ${ }^{\prime} E x o$ isomer. ${ }^{8}$ Data taken from ref. 1 . substituted metal aluminum hỵdrides. ?

Caboxylic Acids and Acyl Derivatives (Table 4). The reaction of carbosylic acids with the reagent evolved only partial hydrogen at $0^{\circ} \mathrm{C}$. and the subsequent reduction also proceed very slowly. However, waming the reaction mixture to $25^{\circ} \mathrm{C}$ enhanced the reaction rate. achieving a quantitative hydrogen evolution and a rapid reduction to the alcohol stage. This reaction pattern is quite similar to that with SCAH. that the rate of reaction with LCAH appears to be relatively faster than that with SCAH. ${ }^{1}$

On the other hand, all of the acid chlorides examined were

Table 4. Reaction of Representative Carbosylic Acids and Acyl Derivatives with Lithium and Sodium Cyanoaluminum Hydrides in Tetrahydrofuran ${ }^{a}$

\begin{tabular}{|c|c|c|c|c|}
\hline \multirow{2}{*}{ Compound } & \multirow{2}{*}{$\begin{array}{c}\text { Temp } \\
\left({ }^{\circ} \mathrm{C}\right)\end{array}$} & \multirow{2}{*}{ Time $(\mathrm{h})$} & \multicolumn{2}{|c|}{ Yield of alcohol $(\%)^{b}$} \\
\hline & & & $\mathrm{LiAlH}_{3} \mathrm{CN}$ & $\mathrm{N} \mathrm{AllH}_{3} \mathrm{CN}^{\mathrm{c}}$ \\
\hline \multirow{3}{*}{ caproic acid } & 0 & 24 & $52^{d 7}$ & $38^{\circ}$ \\
\hline & 25 & 3 & $99^{\prime}$ & $96^{\mathrm{z}}$ \\
\hline & & 6 & 99.7 & 97 \\
\hline \multirow{6}{*}{ benzoic acid } & 0 & 6 & $42^{h}$ & $33^{i}$ \\
\hline & & 24 & 54 & 41 \\
\hline & 25 & 3 & 85 & \\
\hline & & 6 & 95 & $49^{k}$ \\
\hline & & 24 & 97 & 86 \\
\hline & & 48 & 97 & 98 \\
\hline \multirow{2}{*}{ caproyl chloride } & 0 & 0.5 & 100 & $96^{m}$ \\
\hline & & 3 & 100 & 96 \\
\hline \multirow{2}{*}{ benzoyl chloride } & 0 & 0.5 & 100 & $98^{\prime \prime}$ \\
\hline & & 3 & 100 & 98 \\
\hline
\end{tabular}

"A 1.1 equiv of reagent utilized: $0.5 \mathrm{M}$ concentration. "Analved by GC with a suitable internal standard. "Data taken from ref. 1. "A 0.92 equir of

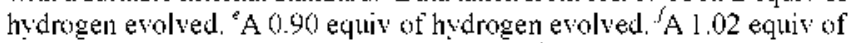
hydrogen evolved and no aldehyde detected. ${ }^{z} \mathrm{~A} 0.96$ equiv of hydrogen evolyed and $3^{\circ} \%$ of caproaldehyde formed. "A 0.72 equiz of hydrogen evolved. 'A 0.67 equiv of hydrogen evolved and $2^{\circ}$ o of benzaldehyde formed. 'A 1.03 equir of hydrogen evolyed. ${ }^{k} \mathrm{~A} 0.94$ equiv of hydrogen evolyed. $3^{\prime} \%$ of benzaldehyde formed. ${ }^{n} 4^{0}, j$ of caproaldehyde formed. "2:0 of benzaldehy de formed. 
Table 5. Reaction of Representative Esters with Lithimn and Sodium Cyanoaluminum Hydrides in Tetrahydrafuran at $0^{\circ} \mathrm{C}^{a}$

\begin{tabular}{|c|c|c|c|c|}
\hline \multirow{2}{*}{ Compound } & \multirow{2}{*}{$\begin{array}{c}\text { Reagent/ } \\
\text { Compd }\end{array}$} & \multirow{2}{*}{$\begin{array}{c}\text { Time } \\
\text { (l) }\end{array}$} & \multicolumn{2}{|c|}{ Yield of alcohol $(\%)^{b}$} \\
\hline & & & \multicolumn{2}{|c|}{$\mathrm{LiAlH}_{3} \mathrm{CN} \mathrm{NaAlH}{ }_{3} \mathrm{CN}$} \\
\hline \multirow{5}{*}{ ethyl caproate } & 0.34 & 6 & 23 & 21 \\
\hline & & 24 & 28 & 25 \\
\hline & 1.1 & 0.5 & 99 & 97 \\
\hline & & 1 & 99.9 & 99 \\
\hline & & 3 & & 99.9 \\
\hline \multirow{5}{*}{ ethyl benzoate } & 0.34 & 6 & 25 & 24 \\
\hline & & 24 & 31 & 27 \\
\hline & 1.1 & 0.5 & 90 & 80 \\
\hline & & 1 & 99.9 & 98 \\
\hline & & 3 & & 99.9 \\
\hline phenyl acetate & 1.1 & 0.5 & 100 & 100 \\
\hline isoprophenyl acetate & 1.1 & 0.5 & 100 & 100 \\
\hline
\end{tabular}

"A $0.5 \mathrm{M}$ concentration. "Analyzed by GC with a suitable internal standard. 'Data taken from ref. 1.

rapidly reduced to the corresponding alcohols by the reagent within $0.5 \mathrm{~h}$ at $0^{\circ} \mathrm{C}$. which appears exactly same as that by $\mathrm{SCAH}^{1}$

Esters (Table 5). The reaction of esters, such as ethyl caproate and ethyl benzoate. with a calculated amount of
Table 6. Reaction of Representative Epoxides with Lithium and Sodium Cyanoaluminum Hydrides in Tetrahydrofuran at 0 " $\mathrm{C}^{a}$

\begin{tabular}{|c|c|c|c|}
\hline \multirow{2}{*}{ Compound } & \multirow{2}{*}{$\begin{array}{c}\text { Time } \\
\text { (h) }\end{array}$} & \multicolumn{2}{|c|}{ Yield of alcohol $(\%)^{t}$} \\
\hline & & $\mathrm{LiAlH}_{3} \mathrm{CN}$ & $\mathrm{NaAlH}_{3} \mathrm{CN}^{\epsilon}$ \\
\hline \multirow{4}{*}{ 1,2-butylene oxide } & 3 & 86 & 35 \\
\hline & 6 & 92 & 42 \\
\hline & 12 & 99 & 75 \\
\hline & 24 & $99^{\mathrm{d}}$ & $100^{7}$ \\
\hline \multirow{5}{*}{ styrene oxide } & 3 & 58 & 52 \\
\hline & 6 & 82 & 54 \\
\hline & 12 & 98 & 78 \\
\hline & 24 & $99.9^{\circ}$ & 96 \\
\hline & 48 & & $99.9^{\prime}$ \\
\hline
\end{tabular}

"An equivalent of reagent utilized: $0.5 \mathrm{M}$ concentration. "Analyzed by GC witl a suitable intemal standard. "Data taken from ref. 1. "One hundred ${ }^{\circ}$ o of 2-butanol. "A nnixture of 1 -phenylethatol $\left(93^{\circ} \cdot 0\right)$ and 2-phenylethanol $\left(7^{\circ} \cdot 0\right)$. A mixture of 1 -phenvlethanol $\left(84^{\circ} \cdot 0\right)$ and 2 -phenvlethanol $\left(16^{n} \%\right)$

LCAH (i.e. I equiv of hydride) at $0^{\circ} \mathrm{C}$ failed to produce the corresponding aldehydes, showing a slow further reduction to the alcohol stages. All of the esters examined in this study were rapidly reduced with 1.1 equiv of the reagent (i.e. 3.3 equiv of hydride) within $1 \mathrm{~h}$ at $0^{\circ} \mathrm{C}$ to give quantitative y ields of the corresponding alcohols. In this case. the rate of reaction with LCAH also appears to be faster than that with SCAH. ${ }^{1}$

Table 7. Reaction of Representative Amides and Nitriles with Lithium and Sodium Cyanoaluminum Hydrides in Tetrahỵdrofuran

\begin{tabular}{|c|c|c|c|c|c|c|}
\hline \multirow{2}{*}{ Compound } & \multirow{2}{*}{$\begin{array}{l}\text { Reagent/ } \\
\text { Compd }\end{array}$} & \multirow{2}{*}{$\begin{array}{l}\text { Temp. } \\
\left(0^{\circ} \mathrm{C}\right)\end{array}$} & \multirow{2}{*}{$\begin{array}{l}\text { Time } \\
\text { (h) }\end{array}$} & \multirow{2}{*}{ Product } & \multicolumn{2}{|c|}{ Yield $(\%)^{b}$} \\
\hline & & & & & $\mathrm{LiAlH}_{3} \mathrm{CN}$ & $\mathrm{NaAlH}_{3} \mathrm{CN}^{2}$ \\
\hline \multirow[t]{8}{*}{ caproamide } & 2 & 25 & 6 & n-hexylamine & $91^{d}$ & $89^{e}$ \\
\hline & & & 24 & & 96 & 94 \\
\hline & & & 48 & & 99 & 98 \\
\hline & & & 72 & & 99 & 98 \\
\hline & & & 120 & & & \\
\hline & 2 & retlux & 3 & & 96 & \\
\hline & & & 6 & & 96 & \\
\hline & & & 24 & & 98 & \\
\hline \multirow[t]{4}{*}{ benzamide } & 2 & 25 & 6 & benzylamine & $9 \mathrm{I}^{\prime}$ & $90^{g}$ \\
\hline & & & 24 & & 97 & 92 \\
\hline & & & 48 & & 99 & \\
\hline & & & 72 & & 99 & 99 \\
\hline K, K-methylcaproamide & 2 & 0 & 0.5 & $N, N$-dimethylhexylamine & 100 & 100 \\
\hline Ardimethylbenzamide & 1 & 0 & 0.5 & $N$-dimethylbezylamine & 100 & 100 \\
\hline \multirow[t]{4}{*}{ capronitrile } & 1 & 25 & 3 & n-hexylamine & $57^{\prime \prime}$ & $47^{i}$ \\
\hline & & & 24 & & 93 & 73 \\
\hline & & & 48 & & 99.9 & 95 \\
\hline & & & 72 & & 99.9 & 99.9 \\
\hline \multirow[t]{4}{*}{ benzonitrile } & 1 & 0 & 3 & benzylamine & 65 & 47 \\
\hline & & & 6 & & 93 & 91 \\
\hline & & & 12 & & 99.9 & 98 \\
\hline & & & 24 & & 99.9 & 98 \\
\hline
\end{tabular}

"A $0.5 \mathrm{M}$ concentration. "Analyzed by GC with a suitable internal standard. 'Data taken from ref. 1. "A 1.94 equiv of hydrogen efolved. "A 1.92 equiz: of hydrogen evolved. $f_{A} 1.61$ equif of hydrogen evolved. ${ }^{8}$ A 1.51 equir of hydrogen evolved. ${ }^{A} 0.07$ equir af hydrogen evolved. ${ }^{j} \mathrm{~A} 0.08$ equiv of hydrogen evolved. 
Table 8. Reaction of Representative Sulfur Compounds with Lithium and Sodium Cyanoaluminum Hydrides in Tetrahydrofuran ${ }^{q}$

\begin{tabular}{|c|c|c|c|c|c|}
\hline \multirow{2}{*}{ Compound } & \multirow{2}{*}{ Temp. $\left({ }^{\circ} \mathrm{C}\right)$} & \multirow{2}{*}{ Tune (h) } & \multirow{2}{*}{ Product } & \multicolumn{2}{|c|}{ Yield $(\%)^{b}$} \\
\hline & & & & $\mathrm{LiAlH}_{3} \mathrm{CN}$ & $\mathrm{NaAlH}_{3} \mathrm{CN}^{2}$ \\
\hline \multirow[t]{3}{*}{ diphenyl disulfíde } & 0 & 0.5 & benzenethiol & $200^{d}$ & 190 \\
\hline & & 1 & & 200 & 198 \\
\hline & & $\hat{3}$ & & & $200^{e}$ \\
\hline \multirow[t]{3}{*}{ di-n-butyl disulfide } & 0 & 0.5 & butanethiol & $201^{f}$ & 182 \\
\hline & & 1 & & 200 & 198 \\
\hline & & 3 & & & $200^{\circ}$ \\
\hline phenyl-n-propyl sulfide & 0 & 3 & & 0 & 0 \\
\hline dinnethyl sulfoxide & 25 & 0.5 & dimethyl sulfïde & $100^{h}$ & $100^{i}$ \\
\hline diphenyl sulfone & 25 & 24 & & 0 & 0 \\
\hline
\end{tabular}

"A 1.1 equiv of reagent utilized: $0.5 \mathrm{M}$ concentration. "Analyzed by GC with a suitable internal standard. "Data taken from ref. $1 .{ }^{d} \mathrm{~A} 0.98$ equiv of hydrogen evolved. "A 0.98 equiv of hydrogen evolved. "A 1.01 equiv of hydrogen evalved. "A 0.99 equiv of hydrogen evolyed. "A 0.99 equir of hydrogen evolved. 'A 1.00 equiv of hydrogen evolved.

Epoxides (Table 6). The reaction of LCAH with epoxides examined appeared faster than that of $\mathbf{S C A H} .{ }^{3}$ requiring $12 \sim$ $24 \mathrm{~h}$ at $0^{\circ} \mathrm{C}$ to complete the reduction to alcohols. The reaction toward 1,2-butylene oxide showed a $100 \%$ regioselectivity to yield only 2-butanol. whereas the reaction toward styrene oxide yielded a mixture of $93 \% 1$ - and $7 \% 2$-phenylethanol. SCAH also showed a $100 \%$ selectivity in the reduction of 1.2-buty lene oxide to give pure 2-butanol, but the selectivity appeared in the reduction of sty rene oxide was somewhat lower than that with LCAH, the product consisting of $84 \%$ Iand 16\%2-pheny lethanol.

Amides and Nitrides (Table 7). Primary amides. such as caproamide and benzamide. evolved $1.6 \sim 1.9$ equiv of hydrogen at $25^{\circ} \mathrm{C}$ with the first equiv of hydrogen evolving rapidly and the second slowly. However. in both cases. the reduction proceeded at a relatively fast rate $\left(48 \mathrm{~h}\right.$ at $\left.25^{\circ} \mathrm{C}\right)$ to produce the corresponding primary amines. the reaction is quite similar to that with SCAH. On the other hand. the reaction of tertiary amides proceeded readily to the corresponding tertiary amines even at $0^{\circ} \mathrm{C}$. Capronitrile reacted slowly, requiring $48 \mathrm{~h}$ at 25 ${ }^{\circ} \mathrm{C}$ to complete the reduction to $n$-hexylamine but benzonitrile was reduced at a relatively faster rate to benzylamine within $12 \mathrm{~h}$ even at $0{ }^{\circ} \mathrm{C}$. In general. the reaction of nitriles with LCAH proceeded at a faster rate than that with SCAH. ${ }^{l}$ In addition to that. the quantity of hydrogen evolution due to the reaction of the acidic $\alpha$-hydrogen of capronitrile with $\mathrm{LCAH}$ also appeared to be quite similar to that with SCAH.

Sulfur Compounds (Table 8). Both disulfides examined reacted rapidly with this reagent to produce $2 \mathrm{~mol}$ of thiol per mole of disulfide. In this reaction, l equiv of hydrogen was evolved immediately apparently due to the further reaction of in situ formed thiol (Eq. 2)

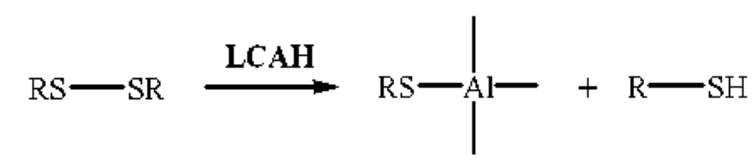

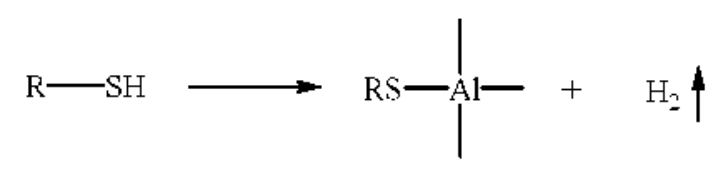

However. sulfides proved to be quite stable to the reagent under the experimental conditions. Dimethyl sulfoxide was readily reduced to the sulfide with the evolution of 1 equiv hydrogen. Finally. diphenyl sulfone was stable even at $25^{\circ} \mathrm{C}$. SCAH also shows a quite similar trend to LCAH in the reaction of sulfur compounds. but the rate of reaction appears to be slower than that of LCAH.

\section{Conclusion}

The approximate rate and stoichiometry of the reaction of a newly'-sỵ'nthesized lithium hydride (LCAH) with selected organic compounds containing representative functional groups was examined in order to compare the behavior of the sodium derivative (sodium cyanoaluminum hydride, SCAH), previously explored. In general. the behavior of LCAH resenbles that of SCAH closely. but the reactivity of LCAH toward functional groups appears to be stronger than that of SCAH. However, the reducing characteristics of both derivatives are significant different from there of the parent lithium and sodium aluminum hydrides. apparently due to the presence of cyano substituent. The cyano substituent. a strong electronwithdrawing group, dininishes the reducing power of the parent metal aluminum hydrides and hence effects the alteration of their reducing characteristics. As a more detailed exploration on these cyano derivatives. these reagents should find their usefulness is selective reduction of organic compounds.

\section{Expenimental Section}

Genelal. The reaction flasks and other glassware used in the experiments were predried at $140^{\circ} \mathrm{C}$ for several hours, 
assembled hot, and cooled under a stream of nitrogen. Syringes were cooled under a stream of nitrogen and assembled. All reactions were carried out under a static pressure of nitrogen in flasks fitted with septum-covered side arms with use of standard techniques for handling air-sensitive materials. ${ }^{5}$

Tetralydrofuran (THF) was distilled from sodium-benzophenone ketyl and stored under dry nitrogen. Lithium alumimum hydride (LAH) was obtained from Aldrich Chemical Co. and used directly without further purification.

Gas chromatographic analysis for products were carried out using a gas chromatograph equipped with $30 \mathrm{~m} \times 0.25 \mathrm{~mm}$ in capillary column of DB-Wax and $25 \mathrm{~m} \times 0.2 \mathrm{~mm}$ in capillary column of HP-FFAP. All GC yields were determined with use of a suitable internal standard and authentic mixture.

Preparation of a Solution of Lithium Cyanoaluminum Hydride (LCAH) in THF. Into an oven-dried, $500 \mathrm{~mL}$. round-bottomed flask with side arm equipped with a magnetic stirrer. was changed $7.63 \mathrm{~g}$ of predried $\mathrm{LiCl}(180 \mathrm{mmol})$ and the flask was attached to mercury bubbler. The flask was then further dried with a flame under a stream of dry nitrogen. To this flask was added $200 \mathrm{~mL}$ of a $0.85 \mathrm{M}$ solution of sodium cyanoaluminum hydride (170 mmol) in THF, ${ }^{1.4}$ and the mixture was stirred vigorously until all the $\mathrm{NaCl}$ precipitated out for 3 h at room temperature. The ${ }^{27} \mathrm{Al}$ NMR spectnim of the clean solution showed a broad singlet at $\sigma 103 \mathrm{ppm}$ (relative to $\mathrm{Al}\left(\mathrm{H}_{2} \mathrm{O}\right)_{6}{ }^{3-}$ ) and the concentration analyzed by measuring the hydrogen evolved upon hydrolysis with $2 \mathrm{NH}_{2} \mathrm{SO}_{4}-\mathrm{THF}(1: 1)$ appeared to be $0.85 \mathrm{M}$.

General Procedure for Detemination of Rate and Identification of Product. The reaction of benzaldehyde is described to examplify the reduction procedure. A $50 \mathrm{~mL}$. oven-dried. round-bottomed flask. equipped with a side arm and reflux condenser connected to a gas meter. was placed in an icewater bath and cooled under dry nitrogen. To this flask were added $0.5 \mathrm{~mL}$ of a $0.85 \mathrm{M} \mathrm{SCAH}$ solution $(5.0 \mathrm{mmol}) .5 \mathrm{mmol}$ of tridecane as an intemal standard and $1 \mathrm{~mL}$ of THF. Two and a half $\mathrm{mL}$ of $2.0 \mathrm{M}$ solution of benzaldehyde $(5.0 \mathrm{mmol})$ in THF was injected into the reagent solution rapidly. This made the mixture $0.5 \mathrm{M}$ both in the reagent and the compound. After $0.5 \mathrm{l}$, an aliquot of the reaction nuxture was withdrawn and hydrolyzed with $2 \mathrm{~N} \mathrm{HCl}$. The aqueous layer was saturated with $\mathrm{K}_{2} \mathrm{CO}_{3}$ and the organic layer was dried with anhydrous $\mathrm{MgSO}_{4}$. GC analysis of the organic layer showed the presence of $100 \%$ benzyl alcohol. In cases where a maximum yield of the reduction product was apparent, no further analysis of the product was performed.

\section{References and Note}

1. Cha, J. S.: Yul, S. I. Bull Korean Chem. Soc. 2008, 29, 2379.

2. (a) Cha, J. S.; Brown, H. C. J. Ong. Chemt 1993, 58, 4727. (b) Cha, J. S.; Brown, H. C. Org. Prep. Proceed hnt. 1994, 26, 459.

3. (a) Brown, H. C.: Dickason, W. C. J. Am Chem Soc. 1970, 92, 709. (b) Ashby, E. C.; Sevenair, J. P.; Dobbs, F. R. J. Org. Chem. 1971, 36, 197. (c) Richer, I. C. lbid. 1965, 30, 324 (d) Haubenstock, H.; Eliel, E. L. J. Am Chem. Soc. 1962, 84, 2363 (e) Brown, H. C. Deck, H. R. Ibid. 1965, 87, 5620. (f) Cha, J. S.; Lee, S. E.; Lee, H. S. Bull. Korean Chem. Soc. 1991, 12, 644. (g) Cha, J. S.; Lee, T. C. Ibid. 1993, 1t, 469. (h) Cha, J. S.; Yu, S. J.; Rol, M. Y; Yi, T. E. lbid. 2008, 29, 2379.

4. A solution of SCAH in THF was prepared by a complex formation reaction of $\mathrm{AlH}_{3}$ and $\mathrm{NaCN}$ in $\mathrm{THF}$. Refer the experimental section of ref. 1

5. Brown, H. C.; Kramer, G. W.; Levy, A. B.; Midland, M. M. Oiganic Sinthesis ria Boranes; Wiley-Interscience: New York, 1975. 